\title{
An Examination of Organizational Determinants Influencing Green Production Adoption by SMEs in Malaysia
}

\author{
Mohd Firdaus Ruslan, Marlina Muhamad, Mohd Fazil Jamaludin \\ Faculty of Business and Management \\ Universiti Teknologi MARA (UiTM) \\ Malaysia \\ firdaus438@kedah.uitm.edu.my
}

\begin{abstract}
Small and Medium Enterprise (SME) is an important economic entity in most country including Malaysia. Statistic from SME Corporation Malaysia shows that currently, there are 645, 136 SMEs and they contribute $32.7 \%$ of Malaysia's Gross Domestic Product (GDP) and the forecast will be $41 \%$ by 2020. Statistics also have indicated that a large portion of the country's environmental problems are associated with the activities of SMEs and it is also believed that SMEs are primary source of environmental problems. Therefore, the participation of SMEs in adopting environmental friendly innovations is crucial in the effort to reduce environmental problems. Past literature have shown that technological determinants have established a stable influence in adoption of environmental innovations researches. However, past researchers have ignored the influence of organizational determinants in influencing adoption of environmental innovations. Thus, this study investigated the organizational determinants such as top management support and quality of human resources in influencing Malaysian SMEs to adopt one of the environmental innovations which is green productions. Data for this study were collected through questionnaire and analyzed by using SPSS. All organizational determinants for this study showed a significant influence on green production adoption. Since this study can be considered as one of the first attempts to empirically investigate organizational factors of green production adoption, the result helped scholars, government and government agencies to understand SMEs' behavior related to green production.
\end{abstract}

\section{Keywords-Green Production; SMEs; Organizational Factor}

\section{INTRODUCTION}

Environmental issues have gained numerous attention by public in past decade since they are exposed to various information from various sources. The public awareness on environmental issues has forced and pressured organization to consider environmental impacts of their business. Most large organizations nowadays adopted few environmental innovations. However, past studies showed that there are very limited involvement of SMEs in adopting these environmental innovations [1]. SMEs are found to adopt "green reactive strategy" where they only respond to the need of fulfilling the environmental regulations and stake holder requests, to react on the changing environment and/or competitors challenge [2]. Most of the SMEs believe that their business have only minimum impacts on the environment since their operations are usually in a small scale and they are only using limited resources [1,3-6]. Therefore, they did not see adopting green innovations as an opportunity and strategy for them.

According to the Census 2011, 645, 136 SMEs are operating in Malaysia, represents $97.3 \%$ of total business establishments [7]. Meanwhile, SMEs contribution to Malaysia's GDP has increased from $29.4 \%$ in 2005 to $32.7 \%$ [7]. Even though SMEs claimed that they are not directly related to current environmental problems [8], statistics have indicated that a large portion of the country's environmental problems is associated with SMEs' activities and it is also believed that SMEs are primary sources of environmental problems [9]. Moreover, by looking at their contribution towards economic growth, country's gross domestic product (GDP) and ratio towards total business establishments, it showed that involvement of SMEs in adopting environmental innovations are important and will determine the future of Malaysia. Therefore, it is important for academicians to identify the determinants that would influence the adoption of environmental innovations by SMEs in Malaysia.

This research is vital since limited studies are found that focused on environmental behavior of SMEs in developing countries. Previous literatures showed that various types of determinants have been tested to see their influence on adoption of various environmental innovations [10-17]. The determinants however, can be classified into three main factors which are technological factor, organizational factor and environmental factor. Most of the past researches have focused on studying the influence of technological factor and ignored the possible influence of organizational and environmental factor. Other than that, past researches also showed that academic researchers were more interested in studying environmental innovations that are more popular and favorable such as green supply chain management. However, realizing that different environmental innovations require different capabilities and will lead to different result, and been influenced by different determinants [18], this study studied the influence of organizational determinants towards one of the environmental innovations which is green production.

This research is funded by "Excellence Fund UiTM Kedah".

RMI file no: 600-RMI/TRS 5/3 (30/2015) 
Green production is a modern manufacturing mode considering both environmental impact and the resources consumption during the whole product life cycle, from design, fabrication, packaging, transportation, usage, recycling, to waste proposal, and its objective to minimize the negative environmental impacts and maximize the utilization rate of resources, as well as to harmonize optimization of economic benefit and social benefit with the maximum integrated benefit [19]. As SMEs possess their own unique characteristics such as limited resources and experts [2], the authors believe that they need to engage in greening their internal processes (ie: production process) before moving towards more complicated innovations such as green supply chain management (GSCM).

\section{LITERATURE REVIEW}

\section{A. Environmental Innovations and Green Production}

Environmental innovations (green innovations) can be defined as a new environmental method, idea, product, process or services that concern on minimizing negative environmental impact of business operations [13]. Although there are various definitions of environmental innovations available nowadays, it can be concluded that any innovations that consider the impacts on environment can be regarded as environmental innovations. This include all green innovations such as green purchasing, green information technology, green production and green supply chain management.

Green production is defined as the application of environmentally and socially sensitive practices to reduce the negative impact of manufacturing activities while, at the same time, harmonizing the pursuit of economic benefits [20]. It is more focused on innovations that is related to the process of creating goods by using processes and systems that are nonpolluting, that conserve energy and natural resources in economically viable, safe and healthy ways for employee, communities and consumers and which are socially and creatively rewarding for all stakeholder for the short and long term future [21]. Four forms of green production by Baines et al. [20] explained completely how organization is considered as green producer. This includes green products, green processes, green use and green end-of-life management. The summary of four forms of green production by Baines et al. [20] as illustrated in Table I.

TABLE I. FOUR FormS OF GREEN PRODUCTION [20]

\begin{tabular}{|l|l|}
\hline \multicolumn{1}{|c|}{$\begin{array}{c}\text { GREEN } \\
\text { POLICIES }\end{array}$} & \multicolumn{1}{c|}{ DESCRIPTION } \\
\hline Green products & $\begin{array}{l}\text { Reducing the negative impact of the materials } \\
\text { included in the product and its packaging }\end{array}$ \\
\hline Green processes & $\begin{array}{l}\text { Reducing the negative impact of the transformation } \\
\text { of raw materials into finished goods }\end{array}$ \\
\hline Green use & $\begin{array}{l}\text { Reducing the negative impact associated to the use } \\
\text { phase }\end{array}$ \\
\hline $\begin{array}{l}\text { Green end-of-life } \\
\text { management }\end{array}$ & $\begin{array}{l}\text { Enabling reuse or recycle of products at the end of } \\
\text { the useful life }\end{array}$ \\
\hline
\end{tabular}

Green products are basically related to reduce the harmful effects of the materials included in the product or its packaging. This includes using the renewable raw materials, avoiding the use of harmful toxic materials and minimizing the use of nonrenewable materials. Green processes on the other hand deals with the process and machine to convert from input to output. This includes machine that reduces air emissions, saving water and energy, minimizing solid and liquid wastes, saving water and energy, and protecting health and safety of production workers, customers and the local community.

Green use concerned with minimizing emissions, waste and energy consumption with the product in use. This can be achieved by transforming the design of the product and implementing innovative technologies to produce environmental friendly products. With the increasing public awareness on environmental issues, the public has started to give attention on this kind of products such as energy saving bulbs, low flow shower head, reusable bag, rechargeable batteries, and many more. Lastly, green end-of-life management is referring to proper recycling and disposal of the product after their useful life. Companies are expected to take responsibility of their products.

\section{B. Organizational Determinants}

In comparison with the technological determinants, organizational determinants still gained less attention especially study focusing on environmental behavior of SMEs in developing country. The organizational determinants imply organization characteristics that may limit or assist adoption of certain innovations. Literature shows that few organizational determinants have been discussed previously [12,15,22-24] .The most common organizational determinant that has been studied previously is organization size [23,24]. Literature showed that organizational size is closely related to adoption of environmental innovations [23-24]. Large organizations are more favorable to adopt environmental innovations rather than small and medium size organizations due to several factors such as available resources, experiences, stakeholder expectations, and financial capabilities.

Other than organizational size, several determinants such as top management support, quality of human resources, greenness level of firm, financial resources, manager's characteristics and environmental management system have been discussed in previous literatures $[12,15,22]$. However, since green production can be considered as new environmental innovations in literature, this study tested the most stable determinants which are quality of human resources and top management support. This is to see whether the result will be different from the others environmental innovation that have been studied in the past.

In general, sufficient organizational resources and qualified organizational capabilities are two relevant organizational characteristics advancing innovation [25]. Qualified human resources are important in adopting innovation because of their competence in learning and innovative capabilities. When the human resources in one organization have adequate learning and innovative capabilities, the adoption process will be faster and easier. On the other hand, organizational encouragement is important to ensure successful implementation of innovation [15]. Without organizational encouragement (such as training, financial) the implementation of any innovation would not be successful. 


\section{HYPOTHESES DEVELOPMENT}

As discussed in previous section (section 2), this study will only examine the influence of organizational determinants, namely the quality of human resource and top management support towards the adoption of green production by Malaysian SMEs. High quality of human resource is helpful for adoption of innovations because of their competent learning and innovative capabilities [15,23]. As the degree to which an organization is receptive to new ideas will influence its propensity to adopt new technologies, a company with higher innovative capacity (staff) will be more likely to successfully implement an advance environmental strategy [26]. Therefore, companies that have qualified human resource will benefit from adopting green innovation [15]. Past studies confirmed that the quality of human resource is positively related to green innovation adoption [12,15,22,23]. Management support especially from top management is essential for green innovation adoption. To ensure a successful any project implementation, organization must sustain more support, especially from the top management [27]. In a case to develop environmental management, top management support is essential because the resources required for adopting green practice will be more easily available and the employees will be more motivated to implement green behavior [28]. Previous studies show that green innovation adoption is somehow had been positively influenced by the top management support $[12,15,22,23]$. Thus, we expect the quality of human resource and top management support to have significant positive relationship with green production adoption and suggested the following hypothesis:

H1: Quality of human resources positively affects green production adoption.

H2: Top management support positively affects green production adoption.

\section{RESEARCH FRAMEWORK}

Based on previous discussion, to study green production adoption, this study will use two organizational determinants which are the quality of human resource and top management support. Therefore, the research framework for this study as presented in Fig. 1.

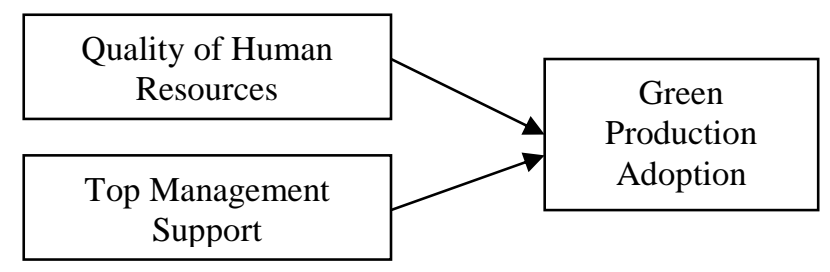

Fig. 1. Research Framework

\section{RESEARCH METHODOLOGY}

The population for this study comprised of 235 Small and Medium (SMEs) manufacturers of chemical and petrochemical products in Selangor. The sampling frame for this study was obtained from the SME Corporation of Malaysia's database.
Selangor has been chosen because of $36 \%$ of total SMEs manufacturing are located in Selangor. While on the other hand, chemical and petrochemical manufacturing companies have been chosen because of chemical and petrochemical facilities are found to be more polluting than other industries [29]. Moreover, this industry is also known to have a high risk working environment. From the population of 235, the total adequate sample is 140 [30]. The data of 140 samples were analyzed by using SPSS.

This study used self-administrated questionnaire. There are 3 parts in the questionnaire. The first part is the demographic information of respondent. The second part is questions related to organizational determinants which are quality of human resources and top management support. Questions in this part were adapted and adopted from literature. Top management support was measured based on the degrees of the company resources support and top management attitudes towards green production while the quality of human resources was measured according to employee's learning and innovative capabilities [31]. According to the reliability coefficients, the smallest value of Cronbach's for this study is 0.772 , which implies, the sampling results are reliable [32]. The values of Cronbach's are presented in Table II.

The last part of the questionnaire is to measure the extent of their willingness to engage in green production activities based on a seven-point numerical scale ranging from 1 ("Not At All") to 7 ("To Great Extent"). For the purpose of this study, adoption of green production was measured by organizations' willingness to adopt green production by Baines et al. [18] namely green product, green process, green use and green end of life management. Organization will try to adopt green production when they have strong willingness [12]. In order to ensure content validity of the measurement instrument (scale), the initial questions related to green production that was designed based on Baines et al. [20] was modified by accommodating five manufacturing managers to ensure that each items is adapted to the manufacturing concept and is interpreted as expected. The seven items of willingness to adopt green production are as presented in Table III.

TABLE II. THE VALUES OF CRONBACH'S

\begin{tabular}{|l|c|}
\hline \multicolumn{1}{|c|}{ Organizational Determinants } & Cronbach's $\boldsymbol{~}$ \\
\hline Quality of human resources & \\
Employees are capable of learning new \\
technologies easily. \\
Employees are capable of sharing \\
knowledge with each others. \\
Employees are capable of using new \\
technologies to solve problem easily. \\
Employees are capable of providing new ideas \\
for our company. \\
Top management support \\
Top management encourages employees to learn \\
green knowledge. \\
Our company provides rewards for employees' \\
green behavior. \\
Our company provides resources for employees \\
to learn green knowledge \\
Top management can help employees dealing \\
with environmental issues
\end{tabular}


TABLE III. SCALE ITEMS OF GREEN PRODUCTION ADOPTION

Survey Items of green production adoption $(N=140)$

To use materials that can reduce the negative impact of our products To use materials that can reduce the negative impact of our products' packaging.

To use processes that can reduce the negative impacts of the transformation process of raw materials into finished goods.

To use processes that consume less energy and resources to produce our products.

To reduce the negative impacts of our products associated to the use phase.

To produce environmental friendly products (consume less energy and low-carbon products)

To produce product that can be reused and recycled at the end of the useful live.

\section{RESULT AND DISCUSSION}

Based on regression analysis, this study revealed that all the organizational determinants affected the adoption of green production by SMEs in Malaysia. In the present regression analysis, the regression assumptions of linearity, normality, independence of residual, and the absence of multicollinearity are all satisfied. Table 1 shows, the model which includes quality of human resources and top management support explains more than $56 \%$ of the variance in green production adoption by Malaysian SMEs. Of these two variables, quality of human resources makes the largest contribution $(\beta=.521)$. The result of this study reveals that all hypotheses are supported. The results of standardize regression as presented in Table IV.

TABLE IV. STANDARDIZE REGRESSION RESULTS

\begin{tabular}{|c|c|}
\hline \multicolumn{2}{|c|}{ Dependent variables: green production adoption } \\
\hline \multicolumn{1}{|c|}{ Predictors } & $\begin{array}{c}\text { Standardize } \\
\text { Coefficient } \beta\end{array}$ \\
\hline Organizational determinants & \\
Quality of human resources & $0.521^{* *}$ \\
Top management Support & $0.370^{* *}$ \\
$\mathrm{R}^{2}$ & 0.568 \\
$\mathrm{Adj} \mathrm{R}^{2}$ & 0.560 \\
$* * \mathrm{P}<0.01$ & \\
\hline
\end{tabular}

The findings of this study confirms that organizational determinants are essential in influencing the adoption of green production by Malaysian SMEs. This is consistent with the studies on other environmental innovations which concludes that regardless of various types of environmental innovations, top management support and quality of human resources are important determinants in influencing adoption of any environmental innovations $[12,15,22,23]$. Therefore, in this case, in order to ensure Malaysian SMEs involvement in adopting green production, government for example need to provide training to equip the staff with knowledge and capabilities related to the innovations. Providing education and training for employee is important for managing environmental issues.

Other than that, top management must also show their continuous support if they are interested to adopt green production since without management support, the adoption process would not be successful. Organizational support gives employees' motivation and resources to adopt any environmental practices including green production [28]. Green production is still regarded as a recent concept for SMEs in Malaysia. Thus, it required numerous support such as financial, moral, training and technical support to ensure successful implementation. Jeyaraj et al. [33] found that the adoption of innovation has positive effects with providing incentive for adoption and ensuring the availability of resources. Moreover, Benito and Benito [34] claimed that green initiatives must be encouraged by top management to ensure its success.

\section{CONCLUSION AND FUTURE RESEARCH}

In conclusion, the results of this study had revealed that the organizational determinants namely quality of human resources and top management support were significant to influence green production adoption by SMEs in Malaysia. This clearly shows that in engaging SMEs to adopt green production, the organization staff itself must possess some level of knowledge and capabilities related to green production. Government agencies must assist SMEs in Malaysia in an effort to equip them with this knowledge and to ensure that they have positive view related to adoption of green production.

This study has contributed in helping to understand the behavior of SMEs in adopting green innovations methods since the existence of study focusing on SMEs in Malaysia and developing country is very limited. As SMEs are important economic entities in most developing countries, this study serves its purpose by being insightful for them. This study also has contributed by bringing out the different views from current literature since this study was focused on green production adoption rather than popular innovations such as GSCM. As discussed previously, SMEs that have limited resources may need to greener their internal process first rather than process that involve external parties. Therefore, green production is more valid in explaining SMEs behavior on environmental issues.

Future researches may look into the characteristics of SMEs itself and comparing them with large size organization in terms of adopting green production with other environmental innovations. As different environmental innovations require different capabilities, it would be very interesting to know which environmental innovation would be preferably adopted based on organization characteristics and capabilities. Other than that, as discussed previously, there are also various determinants that can be studied in future in an effort to understand SMEs behavior on environmental issue.

\section{REFERENCES}

[1] Parker, C., Redmond, J., Simpson, M., Review of interventions to encourage SMEs to make environmental improvements, Environ Plan C Gov policy, 2009, 279-301.

[2] Brío, J., A., Junquera, B., A review of the literature on environmental innovation management in SMEs: implications for public policies, Technovation, 2003, 939-48.

[3] Bradford, J., Fraser E., D., G., Local authorities, 
climate change and small and medium enterprises: identifying effective policy instruments to reduce energy use and carbon emissions, Corp Soc Responsib Environ Manag, 2008, 156-72.

[4] Drake, F., Purvis, M., Hunt, J., Meeting the environmental challenge: a case of win-win or losewin? A study of the UK baking and refrigeration industries, Bus Strateg Environ, 2004, 172-86.

[5] Pimenova, P., Van, D., V., R., The role of support programmes and policies in improving SMEs environmental performance in developed and transition economies, Journal Clea Prod, 2004, 54959.

[6] Tilley, F., The gap between the environmental attitudes and the environmental behaviour of small firms, Bus Strateg Environ, 1999, 238-48.

[7] Malysia, D., O., S., Economic Census 2011 - Profile of Small \& Medium Enterprise, 2011.

[8] Aiyub, K., Arifin, K., Awang, A., Jahi, J., M., Environmental Performance in Small and Medium Enterprise (SMEs) Certified to ISO 14001 in the United Kingdom, Int J Bus Manag, 2009, 7-14.

[9] Malaysia, G., P., N., An Introductory Study on Green Purchasing Activities in Malaysia Green Purchasing Network Malaysia, 2003.

[10] Huang, X., Tan, B., L., Ding, X., An exploratory survey of green supply chain management in Chinese manufacturing small and medium-sized enterprises Pressures and drivers, J Manuf Technol Manag, 2015, 80-103.

[11]Lin, C., Y., Ho, Y., H., The Influences of Environmental Uncertainty on Corporate Green Behavior: An Empirical Study with Small and Medium-Size Enterprises, Soc Behav Personal an Int J, 2010, 691-6.

[12]Lin, C., Y., Ho, Y., H., An Empirical Study on Logistics Service Providers' Intention to Adopt Green Innovations, Journal of Technology Management \& Innovation, 2008, 17-26.

[13] Seman, N., A., A., Zakuan, N., Jusoh, A., Arif, M., S., M., Saman, M., Z., M., The Relationship of Green Supply Chain Management and Green Innovation Concept, Procedia - Soc Behav Sci, 2012, 453-7.

[14] Malaysia, G., P., N., An Introductory Study on Green Purchasing Activities in Malaysia, Green Purchasing Network Malaysia, Green Product, 2003.

[15] Weng, M., H., Lin, C., Y., Determinants of green innovation adoption for small and medium-size enterprises (SMES), African J Bus Manag, 2011, 9154-63.

[16] Yahya, N., Nair, S., R., Piaralal, S., K., Green Practices Adoption Framework for Small and Medium Sized Logistics Firms in Malaysia, Sains Humanika, 2014, 79-84.

[17] Khidir, E., T., Zailani, S., Jayaraman, K., The examination on the drivers for green purchasing adoption among EMS 14001 certified companies in
Malaysia, J Manuf Technol Manag, 2010, 206-25.

[18] Rogers, E., M., Diffusion of Innovations, 4th Edition Simon and Schuster, 1995, 518 p.

[19]Liu, H., Chen, W., Kang, Z., Ngai, T., Li, Y., Fuzzy multiple attribute decision making for evaluating aggregate risk in green manufacturing, Tsinghua Sci Technol, 2005, 627-32.

[20]Baines, T., Brown, S., Benedettini, O., Ball, P., Examining green production and its role within the competitive strategy of manufacturers, J Ind Eng Manag, 2012, 53-87.

[21] Glavič, P., Lukman, R., Review of sustainability terms and their definitions, J Clean Prod, 2007, 1875-85.

[22] Lin, C., Y., Adoption of Green Supply Chain Practices in Taiwan's Logistics Industry, J Int Manag Stud, 2007.

[23] Lin, C., Y., Ho, Y., H., Determinants of Green Practice Adoption for Logistics Companies in China, J Bus Ethics, 2011, 67-83.

[24]Le, Y., Hollenhorst, S., Harris, C., McLaughlin, W., Shook, S., Environmental management: A Study of Vietnamese Hotels, Ann Tour Res, 2006, 545-67.

[25] Damanpour, F., Organizational innovation: a metaanalysis of effects of determinants and moderators, Acad Manag J, Academy of Management, 1991, 55590.

[26]Christmann, P., Effects of "best practices" of environmental management on cost advantage: the role of complementary assets, Acad Manag J, Academy of Management, 2000, 663-80.

[27] Young, R., Poon, S., Top management supportalmost always necessary and sometimes sufficient for success: Findings from a fuzzy set analysis, JPMA, 2013, 943-57.

[28]Dai, J., Montabon, F., L., Cantor, D., E., Linking rival and stakeholder pressure to green supply management: Mediating role of top management support, Transp Res PART E, 2014, 173-87.

[29] Samuel, V., B., Agamuthum, P., Hashim, M., A., Indicators for assessment of sustainable production: A case study of the petrochemical industry in Malaysia, Ecol Indic, 2013, 392-402.

[30] Krejcie, R., V., Morgan, D., W., ACTIVITIES, Educ Psychol Meas, 1970, 607-10.

[31] Tornatzky, L., G., Fleischer, M., Chakrabarti, A., K., Processes of Technological Innovation, Lexington Books, 1990.

[32] Jum, C., Nunnally., Psychometric theory, New York, McGraw-Hill, 1978.

[33] Jeyaraj, A., Rottman, J., W., Lacity, M., C., A review of the predictors, linkages, and biases in IT innovation adoption research, J Inf Technol, Palgrave Macmillan, 2006 .

[34] González, B., J., González, B., Ó., The role of stakeholder pressure and managerial values in the implementation of environmental logistics practices, ,Taylor \& Francis Group, 2007. 